\title{
PENGARUH BAURAN PEMASARAN DALAM MENINGKATKAN VOLUME PENJUALAN MINYAK GORENG MERK TROPICAL PADA PT. FOCUS DISTRIBUSI INDONESIA
}

\author{
Oleh: \\ Suryani \\ Melan Susanty \\ Wati Diska Meliani \\ Program Studi Administrasi Bisnis, Universitas Tulang Bawang - Lampung \\ E-Mail : suryani_mr@yahoo.com
}

\begin{abstract}
ABSTRAK
Tujuan penelitian ini untuk mengetahui pengaruh bauran pemasaran (marketing mix) meliputi produk (product), harga (price), distribusi (distribution), dan promosi (promotion) terhadap peningkatan volume penjualan minyak goreng merk tropical pada PT. Focus Distribusi Indonesia Cabang Lampung baik secara simultan maupun parsial oleh konsumen di wilayah provinsi Lampung. Dalam penelitian pada perusahaan minyak goreng merk Tropical ini adalah bagaimana bauran pemasaran (marketing mix) berpengaruh secara positif dan signifikan terhadap volume penjualan produk. Berdasarkan perhitungan didapat untuk $\mathrm{r}$ - hitung adalah 0,696 apabila dikonsultasikan dengan $r$-tabel untuk tarif signifikan $5 \%$ adalah 0,344 ternyata $r$ hitung lebih besar dari pada r-tabel atau r-hitung $(0,696)>$ r-tabel $(0,344)$ pada tarif signifikan $5 \%$. Dengan demikian bauran pemasaran (marketing mix) mempunyai pengaruh positif dalam meningkatan volume penjualan minyak goreng merk Tropical di PT. Focus Distribusi Indonesia Cabang Lampung. Dari perhitungan diatas dikonsultasikan dengan skala interpretasi nilai $r$ untuk mengetahui antara variabel bebas $(\mathrm{X})$ dengan variabel terikat $(\mathrm{Y})$, interpretasi tersebut didapat bahwa pengaruh bauran pemasaran dalam meningkatkan volume pejualan minyak goreng berada pada skala interprestasi 0,60 - 080 atau pada kategori tinggi (signifikan).
\end{abstract}

Kata kunci: bauran, pemasaran, volume penjualan, minyak goreng Tropical 


\section{PENDAHULUAN}

\subsection{Latar Belakang Masalah}

Dalam dunia pemasaran, kita mengenal istilah bauran pemasaran. Menurut Kotler dan Armstrong, bauran pemasaran adalah sejumlah alat pemasaran yang digunakan perusahaan untuk meyakinkan obyek pemasaran atau target pasar yang dituju (Marketing Mix is the set of marketing tools that the firmuses to pursue its marketing objectives in the target market). Bauran pemasaran merupakan seperangkat alat pemasaran khusus yang digunakan perusahaan terdiri dari produk (product), harga (price), promosi (promotion), dan tempat (place) atau distribusi (distribution). Sekarang ini perusahaan-perusahaan yang siap berkompetisi dalam pangsa pasar minyak goreng yang bermerk hanya 20\%. Posisi persaingan antara industri minyak goreng semakin ketat dan pada gilirannya akan berpengaruh terhadap volume penjualan industri produk minyak goreng.

\section{Tabel 1}

Pemakaian minyak goreng merk Tropical tahun 2012 di Bandar Lampung

\begin{tabular}{|l|l|r|r|} 
No. & BULAN & LITER & \multicolumn{1}{l|}{ RUPIAH } \\
\hline 1. & Januari & 149.736 & 1.746 .263 .180 \\
\hline 2. & Februari & 163.716 & 2.037 .941 .719 \\
\hline 3. & Maret & 99.048 & 1.253 .715 .285 \\
\hline 4. & April & 124.800 & 1.535 .483 .939 \\
\hline 5. & Mei & 103.476 & 1.263 .831 .109 \\
\hline \hline 6. & Juni & 99.984 & 1.211 .330 .345 \\
\hline 7. & Juli & 157.140 & 1.894 .090 .591 \\
\hline 8. & Agustus & 103.104 & 1.267 .557 .869 \\
\hline 9. & September & 92.640 & 1.130 .904 .686 \\
\hline 10. & Oktober & 77.400 & 926.694 .521 \\
\hline 11. & November & 40.524 & 490.834 .438 \\
\hline 12. & Desember & 72.000 & 857.917 .485 \\
\hline
\end{tabular}

Sumber : PT. Focus Distibusi Indonesia Lampung, 2013

Strategi-strategi pemasaran yang diterapkan oleh setiap perusahaan kerap kali timbul permasalahan di lapangan. Sampai saat ini produk minyak goreng merk Bimoli masih menjadi market leader di sektor minyak goreng sawit bermerk, namun banyak produk sejenis muncul di pasaran yang mengambil pangsa pasar Bimoli, seperti merk Tropical, Filma, Sunco, Sania, Fortune, Forvita, dan lain sebagainya.

\subsection{Identifikasi dan Rumusan Masalah}

Identifikasi masalah dalam penelitian ini adalah:

1. Bagaimana promosi minyak goreng Tropical?

2. Bagaimana kualitas minyak goreng Tropical ?

3. Bagaimana saluran distribusi dari minyak goreng Tropical ?

4. Bagaiman intensitas pembelian konsumen dari minyak goreng Tropical ?

\subsection{Tujuan dan Kegunaan Penelitian}

Adapun tujuan yang dicapai dalam penelitian ini adalah :

1. Untuk mengetahui strategi promosi dari minyak goreng Tropical

2. Untuk mengetahui kualitas dari minyak goreng Tropical

3. Untuk mengetahui saluran distribusi dari minyak goreng Tropical

4. Untuk mengetahui intensitas pembelian konsumen dari minyak goreng Tropical

\subsection{Kerangka Pemikiran}

Dengan adanya kerangka kerja akan menjadi dasar dalam pengambilan kebijakan sehingga pekerjaan akan lebih terarah sesuai dengan bagian-bagian secara sistematis, juga merupakan faktor-faktor yang berguna dalam merumuskan strategi pemasaran berdasarkan komponen bauran pemasaran (Marketing Mix).

Strategi pemasaran 4P merupakan kumpulan alat pemasaran taktis yang terdiri dari produk (product), harga (price), tempat (place), dan promosi (promotion) yang dipadukan agar menghasilkan respon yang diinginkan pasar. 


\subsection{Hipotesis}

Menurut Gay, Mills, Airasian (2009:71) Zikmund (1997:112), Hipotesis adalah proposisi atau dugaan belum terbukti bahwa tentatif men - jelaskan fakta atau fenomena, serta kemungkinan jawaban atas pertanyaan-pertanyaan penelitian. Sedangkan menurut Erwan Agus Purwanto dan Dyah Ratih Sulistyastuti (2007:137), bahwa hipotesis adalah pernyataan atau tuduhan bahwa sementara masalah penelitian yang kebenarannya masih lemah (belum tentu benar) sehingga harus diuji secara empiris. Maka hipotesis dalam penelitian ini terdapat pengaruh positif antara bauran pemasaran (4P) tehadap volume penjualan produk minyak goreng merk Tropical.

\subsection{Operasianal Variabel}

Variabel penelitian adalah segala sesuatu yang berbentuk apa saja yang ditetapkan oleh peneliti untuk dipelajari sehingga diperoleh informasi tentang hal tersebut, kemudian ditarik kesimpulannya (Sugiyono, 2016:38). Sesuai dengan judul penelitian yang dipilih penulis yaitu Pengaruh Bauran dalam Meningkatkan Volume Penjualan Minyak Goreng merk Tropical pada PT. Focus Distribusi Indonesia. Maka penulis mengelompokkan variabel yang digunakan dalam penelitian ini menjadi variabel independen $(\mathrm{X})$ dan variabel dependen (Y). Adapun penjelasannya sebagai berikut:

\section{Variabel bebas (independent variable)}

Variabel bebas (X) sering disebut sebagai varabel stimulus, predictor, abtecedent. Variabel bebas adalah variabel yang mempengaruhi atau yang menjadi sebab perubahannya atau timbulnya variabel independen/terikat (Sugiyono, 2016:39). Dalam penelitian ini variabel independen yang diteliti adalah Bauran Pemasaran.
Pengertian Bauran Pemasaran menurut William J. Stanston (2006:30), "Marketing Mix is the term that is used to describe the combination of the four inputs that constitute the core of an organization's marketing system. These four elements are the product offering, the price structure, the promotion activities, and the distribution system." (Bauran Pemasaran adalah istilah yang digunakan untuk menggambarkan kombinasi dari empat input yang merupakan inti dari sistem pemasaran organisasi. Keempat elemen tersebut adalah penawaran produk, struktur harga, kegiatan promosi dan sistem distribusi). Jadi, indikator variabelnya :

a. Produk (Product)

b. Harga (Price)

c. Promosi (Promotion)

d. Sistem Distribusi (Distribution)

\section{Variabel terikat (dependent} variable)

Variabel terikat $(\mathrm{Y})$ adalah apa yang anda ukur dalam percobaan dan apa yang dipengaruhi selama percobaan. Variabel terikat merespons variabel bebas. Disebut dependen karena tergantung pada variabel independen. Dalam penelitian ini, yang menjadi variabel terikatnya adalah volume penjualan.

Penjualan merupakan tujuan utama dilakukannya kegiatan suatu perusahaan. Dalam menghasilkan barang/jasa, perusahaan harus dapat menjual produknya kepada konsumen. Oleh karenanya penjualan memegang peranan penting bagi perusahaan agar produk yang dihasilkan dapat terjual. 
Menurut Freddy Rangkuti (2009:207), Volume Penjualan adalah pencapaian yang dinyatakan secara kuantitatif dari segi fisik atau volume atau unit suatu produk. Volume penjualan merupakan suatu yang menandakan naik turunnya penjualan dan dapat dinyatakan dalam bentuk unit, kilo, ton atau liter.

Adapun menurut Kardaniata (2006 : 11) bahwa volume penjualan diartikan sebagai jumlah (kuantitas) hasil produksi perusahaan yang dikonsumsi oleh konsumen.

Yang menjadi operasional variabel dalam penelitian ini adalah produk minyak goreng merk Tropical hasil produksi PT. Focus Distribusi Indonesia. yang di konsumsi oleh konsumen di Bandar Lampung. Adapun Indikator variabelnya adalah:
a. Intensitas pembelian
b. Area perusahaan
c. Jumlah penggunaan per bulan

\section{KAJIAN PUSTAKA}

\subsection{Pemasaran (Marketing)}

Pemasaran merupakan suatu proses sosial dan manajerial dimana individu atau kelompok mendapatkan apa yang mereka butuhkan dan inginkan melalui penciptaan, pewarnaan dan pertukaran segala sesuatu yang benilai dengan orang atau kelompok lain, mengembangkan barang dan jasa, pemuas keinginan, memberikan nilai kepada konsumen dan laba bagi perusahaan. Menurut American Marketing Association, pemasaran adalah suatu proses perencanaan dan menjalankan konsep, promosi, harga, dan distribusi sejumlah ide, barang serta jasa, untuk menciptakan pertukaran yang dapat memuaskan tujuan organisasi dan individu. Adapun menurut Sofyan Assauri (2004:5) mendefinisikan pemasaran sebagai kegiatan manusia yang diarahkan untuk memenuhi keinginan dan kebutuhan melalui proses pertukaran. Pemasaran juga sebagai usaha menyedikan dan menyampaikan barang dan jasa yang tepat kepada orang-orang yang tepat dan waktu serta harga yang tepat dengan promosi dan komunikasi yang tepat.

\subsection{Bauran Pemasaran (Marketing Mix)}

Bauran pemasaran adalah kumpulan dari variabel-variabel pemasaran yang dapat dikendalikan yang digunakan oleh suatu badan usaha untuk mencapai tujuan pemasaran dalam pasar sasaran.

Menurut Stanton dalam Swastha (2008:78), Bauran Pemasaran (Marketing Mix) adalah kombinasi dari 4 variabel atau kegiatan yang merupakan inti dari sistem pemasaran perusahaan yaitu produk (product), harga (price), sitem distribusi (ditribution), dan kegiatan promosi (promotion).

Bahasan 4 variabel Bauran Pemasaran (Marketing Mix) secara singkat dijelaskan seperti berikut:

1. Produk (product) yaitu segala sesuatu (barang atau jasa) yang ditawarkan kepada masyarakat untuk dilihat, dibeli atau dikonsumsi. Produk antara lain product variety, quality, design, feature, brand name.

2. Harga (price) yaitu sejumlah uang yang konsumen bayar untuk membeli produk atau menganti hak milik produk. Harga meliputi last price, discount, allowance, credit terms, and retail price.

3. Tempat/Distribusi (placeldistribution) yaitu kegiatan perusahaan untuk membuat produk yang dihasilkan/dijual dan tersedia bagi pasar sasaran. Tempat meliputi channels, coverage, locations, and transport. 
4. Promosi (promotion) yaitu untuk mengkomunikasikan dan memperkenalkan produk pada pasar sasaran. Variabel promosi antara lain sales promotion, advertising, sales force, public relation, and direct marketing.

\section{METODE PENELITIAN}

Jenis penelitian yang digunakan adalah penelitian Deskriptif. Penelitian deskriptif (descriptive research) adalah salah satu jenis penelitian yang tujuannya untuk menyajikan gambaran lengkap mengenai setting sosial atau dimaksudkan untuk eksplorasi dan klarifikasi mengenai suatu fenomena atau kenyataan sosial, dengan jalan mendeskripsikan sejumlah variabel yang berkenaan dengan masalah dan unit yang diteliti antara fenomena yang diuji.

Menurut Sugiyono (2005:21) menyatakan bahwa metode deskriptif adalah suatu metode yang digunakan untuk menggambarkan atau menganalisis suatu hasil penelitian tetapi tidak digunakan untuk membuat kesimpulan yang lebih luas. Penelitian ini merupakan penyelidikan yang menuturkan, menganalisis dan mengklasifikasikan, studi khusus, studi waktu dan gerak analisa kualitatif, studi kooperatif, atau operasional.

\subsection{Teknik Pengumpulan Data}

Untuk memperoleh data yang diperlukan, penulis menggunakan teknik sebagai berikut:

\section{Studi Kepustakaan}

Referensi yang ada kaitannya dengan permasalahan yang sedang dibahas, masalah analisis bauran pemasaran (marketing mix) dalam meningkatkan volume penjualan minyak goreng merk Tropical pada PT. Focus Distribusi Indonesia.

\section{Studi Lapangan}

Metode yang dipakai dalam mendapatkan data primer menggunakan cara-cara :

a. Observasi

Yaitu pengamatan langsung tentang bauran pemasaran dalam meningkatkan volume penjualan minyak goreng merk Tropical.

b. Angket

Penulis menyusun sejumlah pertanyaan kemudian dibagikan kepada responden sebagai sampel. Agar penulis memperoleh data primer yang dibutuhkan, yang diukur menggunakan skala likert (Likert Summated Ratings) sebagai berikut:

Jawaban A dengan poin 3 adalah baik

Jawaban B dengan poin 2 adalah cukup baik

Jawaban C dengan poin 1 adalah kurang baik.

c. Dokumentasi

Proses pengumpulan data yang dilakukan dengan cara mengumpulkank dengan cara mengumpulkan dokumen yang dibutuhkan di dalam penelitian.

\section{Populasi dan Sampel}

\section{a. Populasi}

Populasi adalah seluruh subyek yang menjadi sasaran dalam suatu penelitian yaitu konsumen minyak goreng di Bandar Lampung.

\section{b. Sampel}

Sampel adalah sebagian atau wakil dari populasi yang akan diteliti dengan menggunakan cara tertentu. (Arikunto, 1986 : 104). Dalam penelitian ini, peneliti menentukan sample sebanyak 33 orang konsumen sebagai responden.

\subsection{Analisa Kualitatif}


Suatu analisa dengan menggunakan suatu uraian- uraian yang berbentuk kalimat dengan cara membandingkan teori-teori yang ada dengan kenyataan yang ada di lapangan (Hadi, 1993).

\section{Pengaruh Bauran Pemasaran (variabel $\mathbf{X}$ )}

\section{Tabel 2}

Tanggapan responden tentang apakah anda selalu menggunakan minyak goreng Tropical.

\begin{tabular}{|l|c|c|}
\hline \multicolumn{1}{|c|}{ Kategori } & f & \% \\
\hline Mengumpulkan & 22 & $67 \%$ \\
\hline $\begin{array}{l}\text { Kadang-kadang } \\
\text { Menggunakan }\end{array}$ & 11 & $33 \%$ \\
\hline $\begin{array}{l}\text { Tidak } \\
\text { Menggunakan }\end{array}$ & - & - \\
\hline Jumlah & $\mathbf{3 3}$ & $\mathbf{1 0 0 \%}$ \\
\hline
\end{tabular}

Sumber : Hasil Angket Mei 2013

Dari tabel 2 diatas menunjukan bahwa 22 responden atau $67 \%$ dari 33 responden selalu menggunakan minyak goreng Tropical.

Sedangkan 11 responden atau $33 \%$ dari 33 responden yang ada menyatakan kadang-kadang mengunakan minyak goreng Topical.

\section{Volume Penjualan minyak} goreng Tropical (variabel Y)

\section{Tabel 3.}

Tangapan responden tentang apakah anda selalu membeli minyak goreng Tropical.

\begin{tabular}{|l|c|c|}
\hline \multicolumn{1}{|c|}{ Kategori } & f & \% \\
\hline $\begin{array}{l}\text { Selalu } \\
\text { Membeli }\end{array}$ & 26 & $79 \%$ \\
\hline Kadang-kadang & 7 & $21 \%$ \\
\hline Tidak Pernah & - & - \\
\hline Jumlah & $\mathbf{3 3}$ & $\mathbf{1 0 0 \%}$ \\
\hline
\end{tabular}

Sumber : Hasil Angket Mei 2013

Dari tabel diatas menunjukkan bahwa 26 responden atau 79 dari 33 responden yang ada menyatakan selalu membeli minyak goreng
Tropical. Sedangkan 7 responden atau 21 responden dari 33 responden yang ada menyatakan bahwa responden yang ada menyatakan kadang-kadang membeli minyak goreng Tropical.

\subsection{Analisa Kuantitatif}

Berdasarkan metode pengumpulan data yang dilakukan melalui daftar pertanyaan maka diharapkan dapat diketahui tingkat hubungan antara pengaruh bauran pemasaran (variabel $\mathrm{X}$ ) dalam meningkatkan volume penjualan minyak goreng tropical (variabel Y).

\section{KESIMPULAN DAN SARAN 4.1. Kesimpulan}

Promosi dan iklan produk minyak goreng merk Tropical dapat dijumpai di media-media nasional seperti TV dan surat kabar. Ada juga program promosi yang sifatnya potongan harga (discount) terdapat di Mal atau Super Market. Kualitas dari minyak goreng tropical terkenal dengan dua kali penyaringan (filtering) dan bebas kolestrol sehinga baik untuk di konsumsi konsumen.

Saluran distribusi dari minyak goreng Tropical mudah ditemui di pasar atau di swalayan dan Super Market sehingga memudahkan konsumen untuk mendapatkannya.

Berdasarkan hasil perhitungan maka didapat untuk r-hitung adalah 0,696 apabila dikonsultasikan dengan r-tabel untuk tarif signifikan 5\% adalah 0,344 ternyata $r$ hitung lebih besar dari pada r-tabel atau rhitung $(0,696)>$ r-tabel $(0,344)$ pada taraf signifikan 5\%. Dengan demikian bauran pemasaran (marketing mix) mempunyai pengaruh yang positif dalam meningkatkan volume penjualan minyak goreng merk Tropical di PT. Focus Distribusi Indonesia Cabang Lampung. 
Dari perhitungan diatas dikonsultasikan dengan skala interpretasi nilai $r$ untuk mengetahui antara variabel bebas (X) dengan variabel terikat (Y), interpretasi tersebut didapat bahwa pengaruh bauran pemasaran dalam meningkatkan volume pejualan minyak goreng berada pada skala interpretasi 0,60 080 atau pada kategori tinggi (signifikan).

\subsection{Saran}

PT. Focus Distribusi Indonesia Cabang Lampung harus terus memperbanyak ide-ide dalam pemasaran minyak goreng Tropical, baik kualitas maupun kemasan (packaging) yang lebih menarik, sehinga dapat menjadi inspirasi yang tidak membosankan bagi konsumen, dan dapat eksis di tengah kompetisi global.

\section{DAFTAR PUSTAKA}

Ali, Hasan, 2013, Marketing dan KasusKasus Pilihan, Yogyakarta : Center for Academic Publishing Service

Alma, Buchari, 2013, Manajemen Pemasaran dan Pemasaran Jasa, Bandung : Alfabeta

Assauri, Sofjan, 2014, Manajemen Pemasaran, (Dasar, Konsep dan
Strategi) Jakarta : PT. Graf Grafindo Persada

Kotler, Philip and Kevin Lane Keller, 2016, Marketing Management, 15th Edition, New Jersey : Pearson Pretice Hall, Inc.

Kotler, Philip and Gerry Armstrong, 2014, Principle of Marketing, 15th Edition, New Jersey : Pearson Pretice Hall, Inc.

Mursid, M. 2013, Manajemen Pemasaran Jakarta : Bumi Literacy.

Tjiptono, Fandy dan Gregorius Chandra, 2012 Pemasaran Strategik, Yogyakarta : Andi

Sugiyono, 2015, Statistika Nonparametris Untuk Penelitian, Bandung : Apfabeta.

Sugiyono, 2013, Statistika Untuk Penelitian, Bandung : Apfabeta.

Swastha, Basu DH, 2010, Azas-Azas Marketing Jakarta : Idhiil

Terry, George R, 2013, Prinsip-prinsip Manajemen, Jakarta : Bumi Aksara 